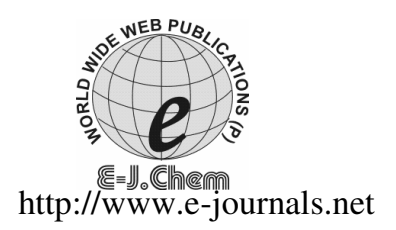

ISSN: 0973-4945; CODEN ECJHAO

E-Journal of Chemistry

2011, 8(1), 49-52

\title{
Reduction of Aldehydes and Ketones to Corresponding Alcohols Using Diammonium Hydrogen Phosphite and Commercial Zinc Dust
}

\author{
K. ANIL KUMAR and D. CHANNE GOWDA* \\ Department of Studies in Chemistry \\ University of Mysore, Manasagangotri, Mysore-570006, India \\ dchannegowda@yahoo.co.in
}

Received 14 January 2010; Accepted 14 March 2010

\begin{abstract}
A mild and an efficient system has been developed for the reduction of aromatic aldehydes and ketones to their corresponding alcohols in good yield using inexpensive commercial zinc dust as catalyst and diammonium hydrogen phosphite as a hydrogen donor.
\end{abstract}

Keywords: Zinc dust, Diammonium hydrogen phosphite, Carbonyl compounds, Catalytic transfer hydrogenation.

\section{Introduction}

Benzylic alcohols and their derivatives occupy an important position in organic synthesis. Preparation of benzylic alcohols and its derivatives from the reduction of carbonyl functional group is of great importance in organic chemistry and there are numerous applications in fine chemical industry and laboratory ${ }^{1}$. A large number of methods including catalytic reduction ${ }^{2}$, Meerwin-ponndorff-verley reduction ${ }^{2}$, hydride transfer reagents ${ }^{3}$, homogeneous catalysis ${ }^{4-6}$ and heterogeneous catalysis $^{7-9}$ systems were reported to be effective towards carbonyl compounds reduction. The reduction of carbonyls to the corresponding alcohols with zinc dust was known to occur under acidic conditions ${ }^{10-11}$. Unfortunately, the reaction gives low chemoselectivity, for example, the reduction of aromatic aldehydes only gives a mixture of arylmethyl acetates and pinacols ${ }^{12}$.

As a part of our research on searching for more environmentally benign methods to reduce carbonyls, we have developed a new and efficient method to reduce aldehydes and ketones to alcohols, using zinc and diammonium hydrogen phosphite, as a reducing agent in toluene/water media at refluxed condition (Scheme 1). The proposed system is highly efficient in reducing both nitro and carbonyl groups; where as most of the existing methods were not able to reduce both functional groups simultaneously. Other functional groups viz., $-\mathrm{Cl},-\mathrm{Br},-\mathrm{CH}_{3},-\mathrm{OCH}_{3}$, and $-\mathrm{OH}$ are tolerated. 
However, it is interesting to note that the presence of electron withdrawing group increases the rate of reduction of carbonyl group whereas the presence of electron releasing group retard the rate of reduction of carbonyl group. This is confirmed by the fact that trimethoxybenzaldehyde has not yield any alcohol even after $24 \mathrm{~h}$ of reduction at reflux temperature.

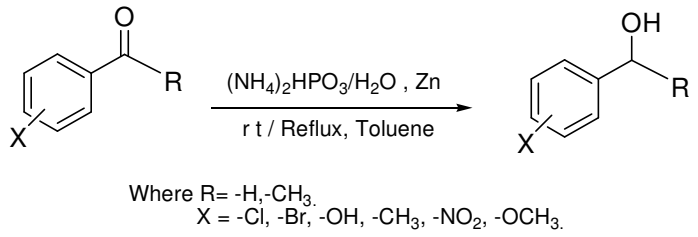

Scheme 1

\section{Experimental}

\section{Materials}

All the nitro compounds were purchased from Aldrich Chemical Company (USA) and zinc dust from SISCO Research Laboratories Pvt. Ltd., Bombay (India). Diammonium hydrogen phosphite was prepared according to the published procedure ${ }^{13-14}$. All the solvents were of analytical grade or were purified according to standard procedures. TLC was performed on silica gel plates obtained from Whatman Inc with the eluting systems chloroform: methanol (90:10) and chloroform: methanol (95:05). For preparative TLC, the plates were prepared from Kieselgel 60GF254 Merck, Darmstadt, and for column chromatography, 60-120 mesh silica gel was used. The melting points were determined by using a Thomas-Hoover melting point apparatus and are uncorrected. IR spectra were recorded on SHIMADZU-FTIR-8300 spectrometer.

General procedure for the reduction of aldehydes and ketones using inexpensive commercial zinc dust and $\left[\left(\mathrm{NH}_{4}\right)_{2} \mathrm{HPO}_{3}\right] \mathrm{H}_{2} \mathrm{O}$ in toluene

In a typical experiment, a solution of diammonium hydrogen phosphite $\left[\left(\mathrm{NH}_{4}\right)_{2} \mathrm{HPO}_{3}\right] \mathrm{H}_{2} \mathrm{O}$ ( 20 mmole) in water $(2 \mathrm{~mL})$ was added drop wise over 5 minute to rapidly stirred mixture of benzaldehyde $(9.7 \mathrm{mmole})$ in toluene $(5 \mathrm{~mL})$ and $\mathrm{Zn}$ dust as a catalyst $(4.5 \mathrm{mmole})$. The resultant mixture was stirred under nitrogen atmosphere for 6-8 hours in refluxed condition. After the completion of reaction (monitered by TLC), the reaction mixture was filtered through celite. The organic layer was evaporated and the residue was dissolved in dichloromethane and washed with $\mathrm{NaHSO}_{4}$ solution then with brine solution. The organic layer was dried over anhydrous $\mathrm{Na}_{2} \mathrm{SO}_{4}$ and the solvent was evaporated under reduced pressure to obtain the desired alcohol compound. The products were purified either by preparative TLC or by column chromatography.

\section{Results and Discussion}

The results given in Table 1 reveal the viability of using zinc and diammonium hydrogen phosphite system for the reduction of aldehydes and ketones to corresponding alcohols. The course of the reaction was monitored by TLC and IR spectra. The work-up and the isolation of the products were easy. Thus, the aldehydes and ketones reduced by this system were obtained in good yields. The products were characterized by comparison of their boiling points or melting points, TLC, IR and ${ }^{1} \mathrm{H}$ NMR spectra with authentic samples. The disappearance of strong absorption band of $1690-1718 \mathrm{~cm}^{-1}$ due to $\mathrm{C}=\mathrm{O}$ (carbonyl) stretching and the appearance of a strong broad absorption bands between $3200-3420 \mathrm{~cm}^{-1}$ for the - $\mathrm{OH}$ (alcoholic) group clearly shows that the aldehydes and ketones were reduced to 
corresponding alcohols. In the case of ortho-nitro benzaldehyde (Entry 7), the nitro group and carbonyl group both underwent reduction to yield hydroxyamine.

Table 1. Reduction of aldehydes and ketones to corresponding alcohols with diammonium hydrogen phosphite in presence of zinc dust

\begin{tabular}{|c|c|c|c|c|c|c|}
\hline \multirow[b]{2}{*}{ Entry } & \multirow[b]{2}{*}{ Substrate } & \multirow[b]{2}{*}{ Time, $\mathrm{h}$} & \multirow[b]{2}{*}{ Product } & \multirow{2}{*}{$\begin{array}{c}\text { Yield }^{\mathrm{a}} \\
\%\end{array}$} & \multicolumn{2}{|c|}{ Melting point, ${ }^{\circ} \mathrm{C}$} \\
\hline & & & & & Found & $\begin{array}{c}\text { Lit } \\
\text { value }\end{array}$ \\
\hline 1 & & $3.0^{*}$ & & 85 & 204-205 & $203-205^{\mathrm{b}}$ \\
\hline 2 & & $1.0^{\S}$ & & 72 & $68-71$ & $70-72$ \\
\hline 3 & & $0.75^{\S}$ & & 75 & $55-58$ & $58-60$ \\
\hline 4 & & $1.5^{\S}$ & & 72 & $78-80$ & 79 \\
\hline 5 & & $2.5^{*}$ & & 70 & $83-85$ & $84-86$ \\
\hline 6 & & $3.0^{*}$ & & 65 & $59-61$ & $58-61$ \\
\hline 7 & & $4.0^{*}$ & & 60 & $80-81$ & $81-83$ \\
\hline 8 & & $4.0^{*}$ & & 60 & 259 & $260^{\mathrm{b}}$ \\
\hline 9 & & - & No reactic & - & - & - \\
\hline 10 & & $3.0^{*}$ & & 65 & $204^{\mathrm{b}}$ & 207 \\
\hline 11 & & $1.0^{\S}$ & & 70 & 119 & $117-120^{\mathrm{b}}$ \\
\hline 12 & & $1.5^{*}$ & & 78 & 69 & $66-68$ \\
\hline
\end{tabular}

\footnotetext{
${ }^{\mathrm{a}}$ Isolated yields are based on single experiment and yields were not optimized

${ }^{\mathrm{b}}$ Boiling point.

*The reaction was carried out under reflux condition

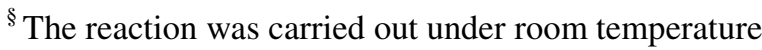




\section{Conclusion}

In conclusion, we wish to report a new system for the reduction of aldehydes and ketones to corresponding alcohols. The yields obtained are comparatively moderate to good. In addition, the catalyst is non-pyrophoric in nature and other interesting behaviour of zinc dust lies in fact that it can be recycled after simple washing with ether and dilute $\mathrm{HCl}$. The process is more economic and makes use of mild reaction condition.

\section{Acknowledgment}

The author K. Anil Kumar wishes to thank Geetha Shishu Shikshana Sangha Institute of Engineering and Technology for Women (GSSSIETW), Mysore for their kind assistance.

\section{References}

1. Ji H B and She Y B, Green Oxidation and reduction; China Petrochemical Press, Beijing, 2005.

2. Larock R C, Comprehensive Organic Transformations: a guide to functional group preparations, $2^{\text {nd }}$ Eds.; Wiley-VCH, New York, 1999.

3. Farajollah Mohanazadeh, Mostafa Hosini and Mahmoud Tajbakhsh, Monatshefe fur Chemie., 2005, 136, 2041.

4. $\quad$ Brandt P, Roth P and Anderssson P G, J Org Chem., 2004, 69, 4885.

5. Liu P N, Deng J G, Tu Y Q and Wang S H. Chem Commun., 2004, 18, 2070.

6. Zhao F Y, Fujita S, Sun J M, Ikushima Y and Arai M, Chem Commun., 2004, 20, 2326.

7. Liu P N, Gu P M, Wang F and Tu Y Q. Org Lett., 2004, 6, 169.

8. Milone C, Ingoglia R, Pistone A, Neri G, Frusteri F and Galvagno S, J Catal., 2004, 222, 348 .

9. Selvam P, Sonavane S U, Mohapatra S K and Jayaram R V, Adv Synth Catal., 2004, 346, 542.

10. Selm R C. Org Prep Int., 1973, 5, 303.

11. Rani B R, Ubukata M and Osada H. Bull Chem Soc Jpn., 1995, 68, 282.

12. Tanaka K, Kishigami S and Toda F, J Org Chem., 1990, 55, 2981.

13. Gmelin handbook of inorganic and organometallic chemistry, Ammonia $8^{\text {th }}$ Ed.; 1936.

14. Lange N A, Handbook of Chemistry, $10^{\text {th }}$ Ed., McGraw-Hill, New York, 1967. 


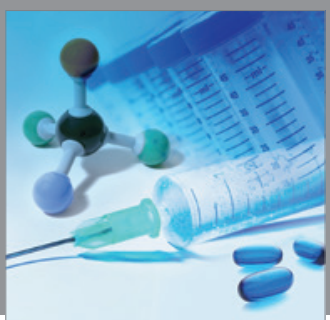

International Journal of

Medicinal Chemistry

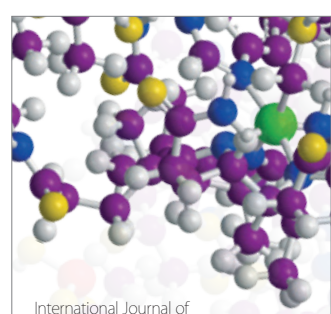

Carbohydrate Chemistry

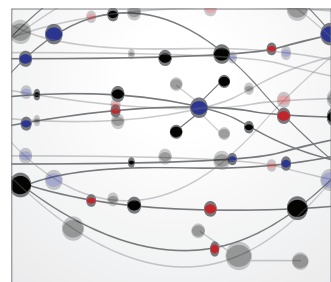

The Scientific World Journal
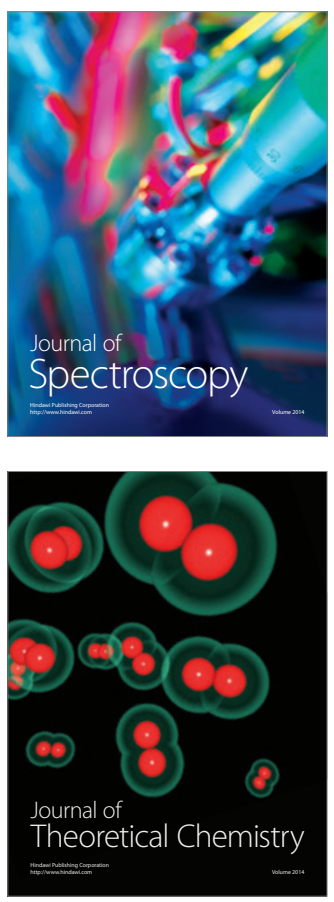
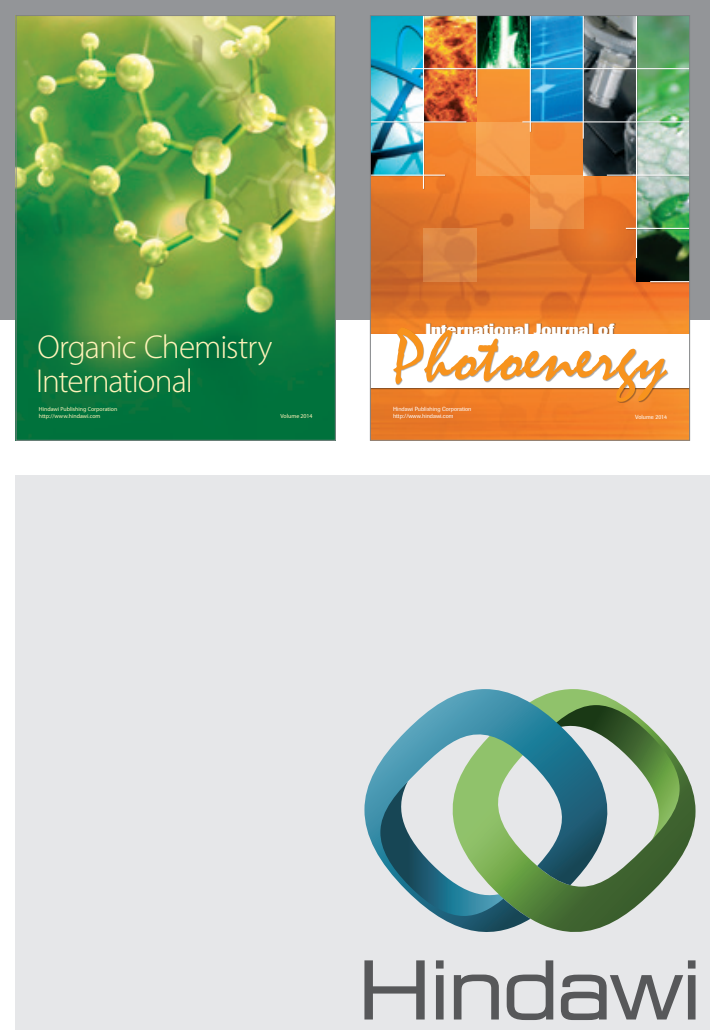

Submit your manuscripts at

http://www.hindawi.com
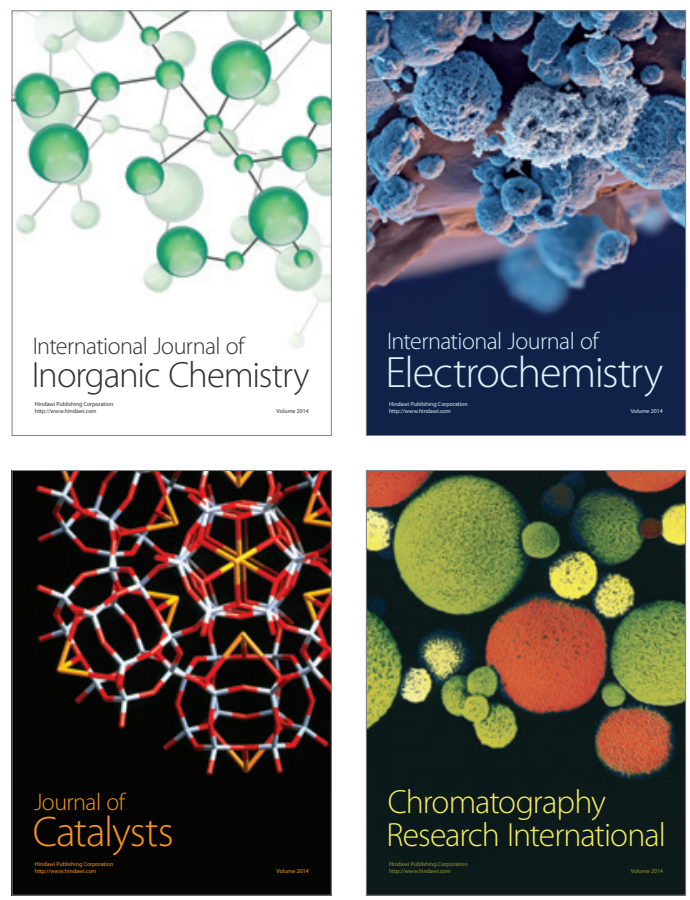
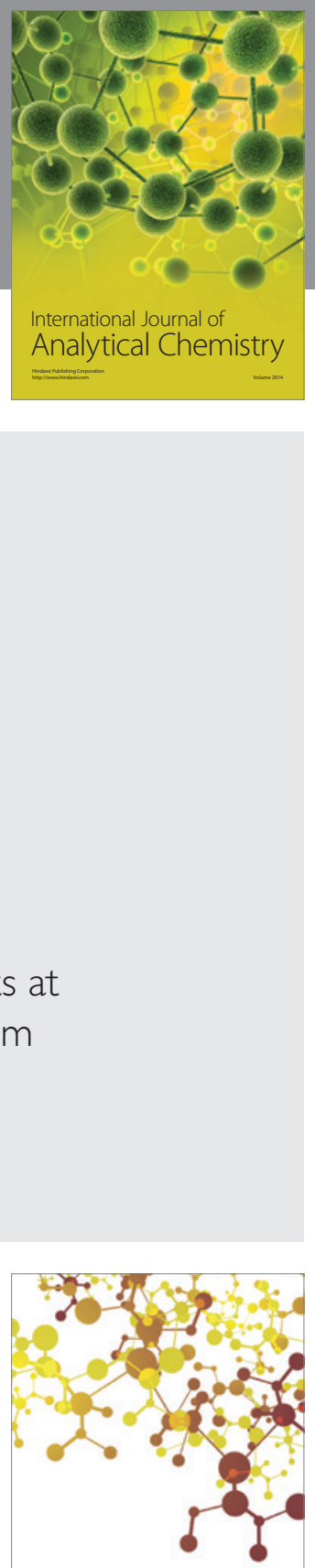

Journal of

Applied Chemistry
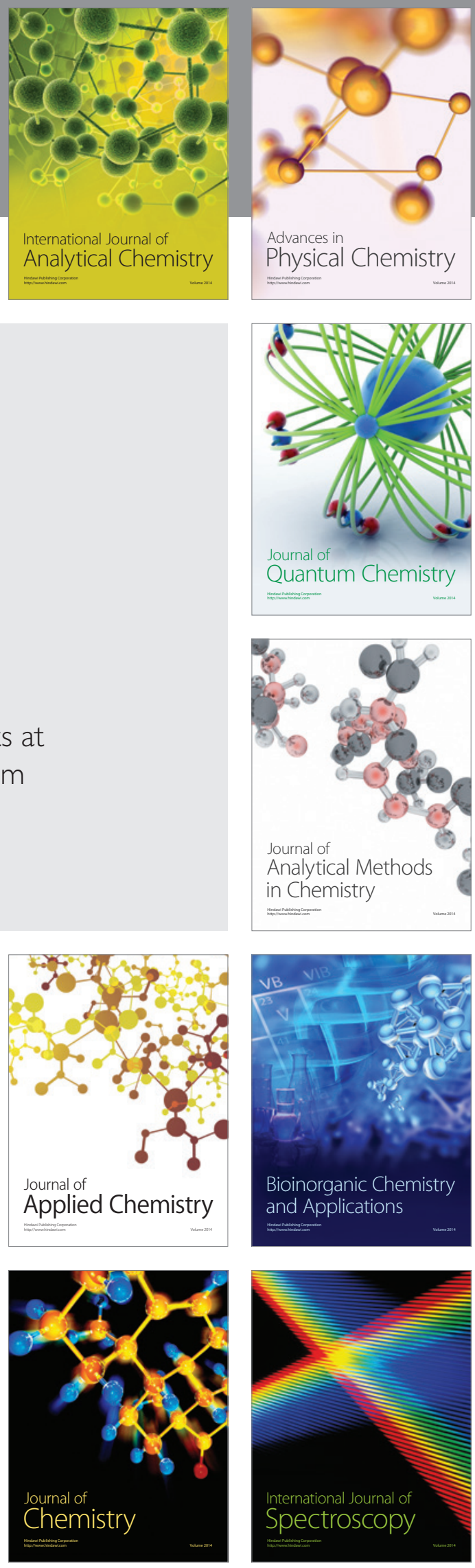